\title{
ASME Section III Stress Analysis of a Heat Exchanger Tubesheet with a Misdrilled Hole and Irregular or Thin Ligaments
}

\author{
Enrique Gomez ${ }^{1}$, Roberto Ruiz ${ }^{1}$ and Robert M. (Con) Wilson ${ }^{2}$ \\ 1. Design \& Analysis Engineering Department, ENSA, Cantabria 39600, Spain \\ 2. Private Consultant, Orlando, Florida USA
}

Received: April 28, 2014 / Accepted: May 20, 2014 / Published: August 25, 2014.

\begin{abstract}
A stress analysis is described for a nuclear steam generator tubesheet with a thin, or irregular ligament, associated with a mis-drilled hole using the rules of ASME (American Society of Mechanical Engineers) B \& PV Section III and non-mandatory Appendix A, Article A-8000 for stresses in perforated flat plates. The analysis demonstrates the proper application of the NB-3200 rules for this special application, with discussion of the differences between an actual tube hole deviation and what is assumed in ASME Appendix A. This is a companion paper to "Technical Justification Supporting Operation with a Tube Installed in a Mis-Drilled Hole of a Steam Generator Tubesheet”.
\end{abstract}

Key words: Heat exchanger, tubesheet, misdrilled hole, irregular ligament, thin ligament, A-8000.

\section{Nomenclature}

$h \quad$ Nominal width of ligament at the minimum cross section, $(P-d)$ (inches)

Nominal distance between hole center lines, pitch (inches)

Thickness of plate exclusive of cladding or corrosion allowance (inches)

$\eta \quad$ Ligament efficiency $=h / P$

$v^{*} \quad$ Effective Poisson's ratio for perforated plate (Fig. A-8131-1)

$E^{*} \quad$ Effective Young's modulus for perforated plate (Fig. A-8131-1) (ksi)

$R^{*} \quad$ The effective radius of the perforated plate $r_{\mathrm{o}}+1 / 4$ $(P-h)$ (inches)

Radial distance from center of plate to center of

$r_{\mathrm{o}} \quad$ outermost hole (inches)

$p_{1}, p_{2} \quad$ Pressures acting on surfaces of the plate (ksi)

$\Delta p \quad$ Differential pressure across the plate (ksi)

$\sigma_{r}{ }^{*} \quad$ Radial stresses in the equivalent solid plate (ksi)

$\sigma_{\theta}{ }^{*} \quad$ Tangential stress in the equivalent solid plate (ksi)

$\sigma_{a}{ }^{*} \quad$ Axial stress in the equivalent solid plate (ksi)

$\tau_{r a}{ }^{*} \quad$ Radial-axial shear stress in the equivalent solid plate (ksi)

Corresponding author: Roberto Ruiz. E-mail:
ruiz.roberto@ensa.es.

\begin{tabular}{|c|c|}
\hline$\sigma_{r}$ & Radial stresses in the tubesheet (ksi) \\
\hline$\sigma_{\theta}$ & Tangential stress in the tubesheet (ksi) \\
\hline$\varepsilon_{r}$ & Radial strain in the tubesheet (ksi) \\
\hline$\varepsilon_{\theta}$ & Tangential strain in the tubesheet (ksi) \\
\hline$\beta$ & $\begin{array}{l}\text { Biaxiality ratio }\left(\sigma_{\mathrm{r}} / \sigma_{\theta} \text { or } \sigma_{\theta} / \sigma_{\mathrm{r}}\right) \text { or }\left(\sigma_{1} / \sigma_{2} \text { or } \sigma_{2} / \sigma_{1}\right) \text {, } \\
\text { where, }-1 \leq \beta \leq 1\end{array}$ \\
\hline$\sigma_{1}^{*}, \sigma_{2}{ }^{*}$ & $\begin{array}{l}\text { Principal stress in the plane of the equivalent solid } \\
\text { plate (A-8142.2) (ksi) }\end{array}$ \\
\hline$\sigma_{\text {ave }}{ }^{*}$ & $\begin{array}{l}\text { Larger absolute value of } \sigma_{r}^{*} \text { or } \sigma_{\theta} *(\mathrm{~A}-8142.1(\mathrm{~b})) \\
\text { (ksi) }\end{array}$ \\
\hline$\sigma_{\text {skin }}$ & Thermal skin stress (ksi) \\
\hline$d$ & Diameter of holes in the tubesheet (inches) \\
\hline$K$ & $\begin{array}{l}\text { Stress multiplier for stresses averaged across the } \\
\text { width of the ligament but not through the tubesheet } \\
\text { thickness (Fig. A-8142-1) }\end{array}$ \\
\hline$Y_{1}, Y_{2}$ & $\begin{array}{l}\text { Stress multipliers for peak ligament stresses (Figs. } \\
\text { A-8142-3 and 4) }\end{array}$ \\
\hline$Y_{\max }$ & $\begin{array}{l}\text { Stress multipliers given in Fig. A-8142-2 as a } \\
\text { function of biaxiality ratio } \beta\end{array}$ \\
\hline$K_{m}$ & $\begin{array}{l}\text { Ratio of total stress in the thin ligament to the total } \\
\text { stress in nominal ligament (Fig. A-8143.2-1) }\end{array}$ \\
\hline$K_{\text {skin }}$ & $\begin{array}{l}\text { Stress multiplier for thermal skin stress (Fig. } \\
\text { A-8153-1) }\end{array}$ \\
\hline$S$ & Stress intensity (A-8142) (ksi) \\
\hline$v$ & Poisson's ratio \\
\hline E & Young's modulus for tubesheet material (ksi) \\
\hline$E_{t}$ & Young's modulus for the tube material (ksi) \\
\hline
\end{tabular}


Mean temperature averaged through the thickness of the tubesheet

$T_{s} \quad$ Temperature of the secondary surface of the tubesheet

$\alpha \quad$ Coefficient of thermal expansion

$t_{t} \quad$ Tube wall thickness (inches)

$p_{s} \quad(\mathrm{ksi})$

$p_{1} \quad$ Pressure in the primary side (ksi)

$p_{2} \quad$ Pressure in the secondary side (ksi)

$p_{i} \quad$ Pressure inside tubes (ksi)

$P_{m} \quad$ Primary membrane stress (ksi)

$P_{m+b} \quad$ Primary membrane plus bending stress (ksi)

$Q \quad$ Secondary stress (ksi)

$F \quad$ Peak stress (ksi)

CUF Cumulative usage factors for fatigue

\section{Introduction}

Perforated plate stress analysis has been performed for decades using a methodology that was established in the early 1960s [1]. That methodology was introduced to the ASME (American Society of Mechanical Engineers) Boiler and Pressure Vessel Code for Nuclear Components (Section III) in the Summer 1966 Addenda to the 1965 Edition as non-mandatory Appendix I, Article I-9 "Stresses in Ligaments" [2]. This same methodology is present with minor editorial changes in the current 2011 Addenda of the 2010 Edition of Section III as Appendix A, Article A-8000 [3]. This methodology allows the tubesheet to be analyzed as if it is a solid plate, followed by the application of stress multipliers that were derived from experiments as a function of the tube hole size and pitch. The conversion of a plate with drilled holes to an equivalent solid plate is accomplished by using a modified Young's modulus and Poisson's ratio that is based on tests of plates with various tube hole diameter-to-pitch ratios or ligament efficiencies.

The original methodology also included a procedure for evaluating stresses for a mis-drilled hole with a thinner than nominal ligament. The mis-drilled hole configuration assumed that the hole was out-of-position through the entire thickness of the tubesheet, i.e., parallel to the neighboring holes.
The stress analysis described in this paper is based on the more realistic as-fabricated condition where the mis-drilled hole is not parallel to the neighboring holes. In this case, the drilling of the hole begins at the appropriate position and then drifts away from the intended path, to exit the opposite side of the tubesheet with an out-of-position condition. The limiting location for this condition is at the thinnest ligament location.

The structural analysis of the tubesheet, channel head, and lower shell complex involves several simplifications. This paper discusses some of them.

The paper is organized as follows: Section 2 describes the geometry of the tubesheet used in the analysis; Section 3 introduces the method for evaluating the stresses in a nominal ligament, developed through Sections 4 to 8; Section 4 clarifies the evaluation of thermal skin stresses; Section 5 includes the method for calculating the stresses in the ligament due to the pressure inside the tubes; Section 6 presents the evaluation of primary stresses; Section 7 presents the evaluation of primary plus secondary stresses and Section 8 shows the peak stress intensity and fatigue; Section 9 starts the evaluation of a thin ligament; Sections 10 shows average stress intensity limit; Section 11 presents peak stress intensity limit ; Section 12 shows peak stress intensity evaluation; Section 13 gives conclusions; Section 14 presents the acknowledgments; finally, Section 15 includes a list of references used.

\section{Geometry of the Tubesheet}

Fig. 1 shows the dimensions of an axisymmetric model of a typical steam generator tubesheet, channel head and lower shell configuration. All parts are constructed using SA-508, Grade 3, Class 2 low alloy steel [8]. The tubesheet that is modeled has 14,440 , 0.75 inch diameter holes for 7,220 U-tubes. For simplicity, the tube outer diameter is assumed to be equal to the hole diameter. The distance of holes (the tube pitch) is 1 inch and the holes are arranged in an equilateral triangular pattern. This produces a 0.25 


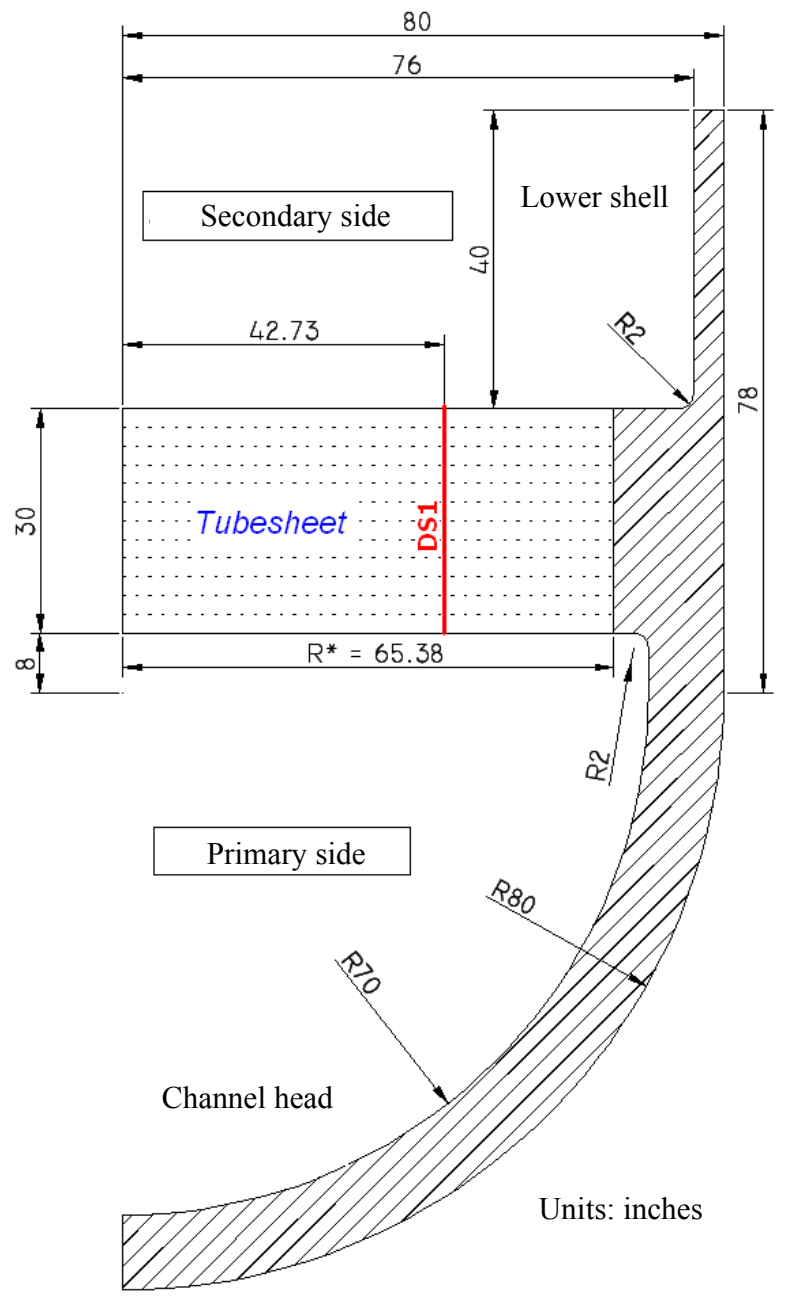

Fig. 1 Tubesheet, channel head, lower shell geometry.

inch nominal, minimum ligament between holes. The ligament efficiency $[\eta=(P-d) / P=h / P]$ is 0.25 . The tubes in the tubesheet holes are Alloy 690 material and have a $t_{t}=0.040$ inch wall thickness.

The actual tubesheet has a hot leg side where the heated reactor coolant enters the steam generator tube bundle. The hot leg side has 7,220 holes, each containing the hot leg end of the 7,220 U-bend tubes. The U-bend tubes transfer heat from the reactor coolant to the secondary side fluid to produce steam, and the reactor coolant exits the bundle through the cold leg side of the tubesheet. The hot leg and cold leg sides of the tubesheet are separated by a non-drilled (solid) tubelane that extends across the full diameter of the tubesheet. The steam generator also has a solid divider plate that joins the tubesheet to the channel head and forces the hot reactor coolant to flow through the U-tubes.

It is possible to evaluate the tubesheet stresses using a 3D finite element model that contains the non-perforated tubelane and the divider plate. However, since the original equivalent solid plate methodology is based on an axisymmetric structure, it is acceptable to treat the pressure boundary as being axisymmetric, assuming the entire tubesheet to be perforated (neglecting the tubelane and divider plate).

The location of the mis-drilled hole used in this analysis is shown in Fig. 2.

The mis-drilled hole is located 42.73 inches from the center of the tubesheet (on the primary side) where the nominal primary side ligament is 0.25 inch. The secondary side ligament is assumed to be $0.1 \mathrm{inch}$. The mis-drilled hole geometry is shown in Fig. 3.

\section{Stress Evaluation-Nominal Ligament}

ASME Section III Appendix A, Article A-8000 [3] provides a methodology for determining stresses in perforated plates. This methodology first calculates the ligament stresses at a nominal ligament and then modifies the result to account for an irregular or thin ligament. Following is a discussion of the stress

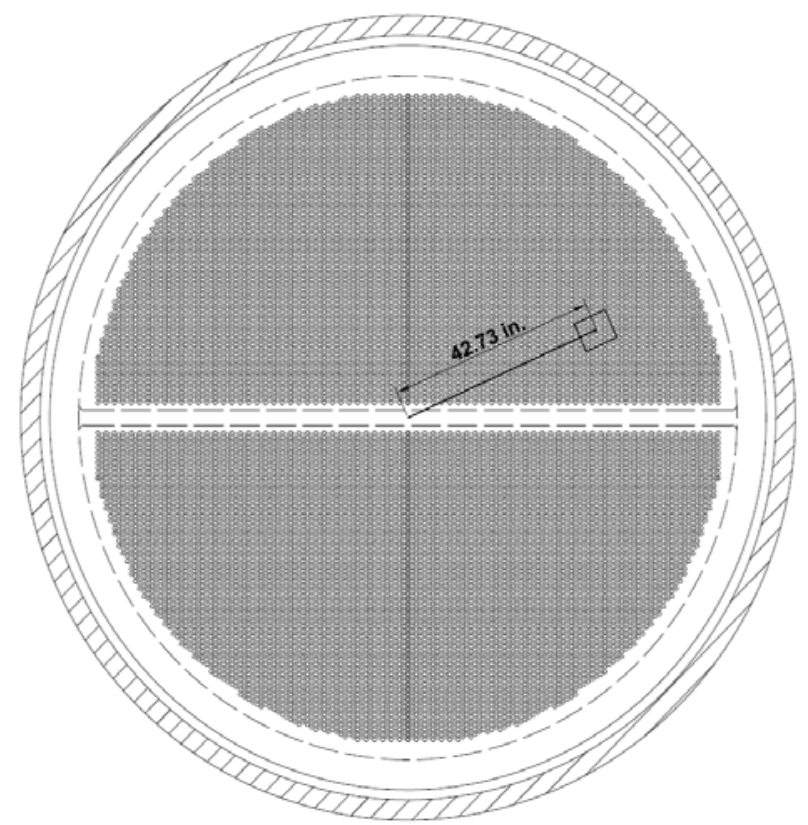

Fig. 2 Location of the mis-drilled hole. 


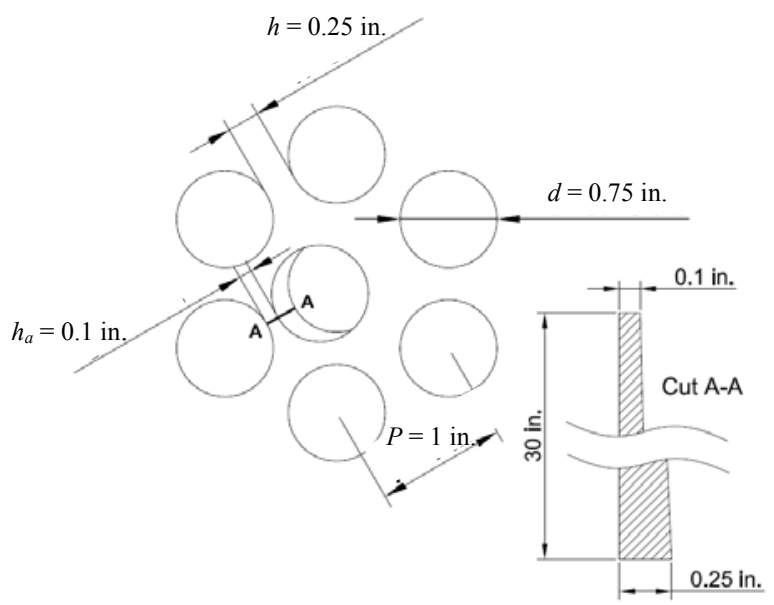

Fig. 3 Geometry of the mis-drilled hole.

analysis of the nominal ligament at the radial position of the mis-drilled hole (i.e., DS1 in Fig. 1).

The tubesheet loadings used in this example include pressure differences and thermal differences for 10 transient events across the tubesheet thickness. The metal temperature in the perforated region of the tubesheet is equal to the tube inside temperature (either reactor coolant hot leg temperature or cold leg temperature) through most of the tubesheet thickness, with the exception of a thin zone at the secondary face where secondary side water cools the tubesheet. The tubesheet surface stresses caused by this local cooling are called thermal skin stresses.

Additional thermal stresses are produced by the thermal interaction between the tubesheet perforated region and the adjacent, non-perforated part of the tubesheet and the attached channel head, and lower shell. These thermal stresses are called gross thermal interaction stresses.
The pressure induced stresses and the gross thermal interaction stresses are calculated using an ANSYS [5] finite element model based on the equivalent solid plate properties as defined by A- 8130 [3]. The secondary side surface temperatures are calculated using the finite element model; but the skin stress is not. The thermal skin stress is calculated using the equation from A-8153 [3]. This is consistent with the recommendations of Slot and O'Donnell $[1,4]$.

The tubesheet stress results at the secondary side location labeled DS1 in Fig. 1 are shown in Table 1 for a unit pressure loading (1,000 psi).

\section{Thermal Skin Stress Evaluation}

The thermal skin stress is calculated using Eq. (24) from A-8153 [3]; $\sigma_{r s k i n}=\sigma_{\theta s k i n}=E \cdot \alpha\left(T_{m}-T_{s}\right) /(1-v)$. A-8153 tells the analyst to use Eq. (23); $\sigma_{\text {skin }}=$ $K_{\text {skin }} \cdot Y_{\max }(P / h) \cdot E \cdot \alpha\left(T_{m}-T_{s}\right) /(1-v)$ when Eq. (24) was intended. The ASME acknowledged this editorial error in response to a 2012 code inquiry [6].

The secondary side tubesheet metal surface temperature $T_{s}$ is calculated by ANSYS for each transient and the tubesheet mean temperature, $T_{m}$ is set equal to the average temperature in the tubesheet, which is the reactor coolant hot leg temperature for purposes of this analysis.

The thermal skin stress is not dependent on the ligament efficiency because the skin effect is localized near the surface of a very thick plate. The thick plate constrains the secondary surface so that its in-plane surface strains $\varepsilon_{r}$ and $\varepsilon_{\theta}$ are zero. This assumption leads to the thermal skin stress equation: $\sigma_{r s k i n}=\sigma_{\theta s k i n}$

Table 1 Tubesheet pressure stresses due to unit loads.

\begin{tabular}{lllll}
\hline $\begin{array}{l}\text { Membrane, } P_{m} \\
@ \text { sec. side node }\end{array}$ & $\begin{array}{l}\sigma_{r}{ }^{*} \\
(\mathrm{ksi})\end{array}$ & $\begin{array}{l}\sigma_{\theta}{ }^{*} \\
(\mathrm{ksi})\end{array}$ & $\begin{array}{l}\sigma_{a}{ }^{*} \\
(\mathrm{ksi})\end{array}$ & $\begin{array}{c}\tau_{r a}{ }^{*} \\
(\mathrm{ksi})\end{array}$ \\
\hline$p_{1}=1 \mathrm{ksi}$ & 0.281 & 0.261 & -0.511 & 0.710 \\
$p_{2}=1 \mathrm{ksi}$ & 0.008 & -0.011 & -0.509 & -0.710 \\
\hline Mem + bend, $P_{m+b}$ & $\begin{array}{l}\sigma_{r}{ }^{*} \\
(\mathrm{ksi})\end{array}$ & $\begin{array}{l}\sigma_{\theta}{ }^{*} \\
(\mathrm{ksi})\end{array}$ & $\begin{array}{l}\sigma_{a}{ }^{*} \\
(\mathrm{ksi})\end{array}$ & $\begin{array}{c}\tau_{r a}{ }^{*} \\
(\mathrm{ksi})\end{array}$ \\
\hline$p_{1}=1 \mathrm{ksi}$ side node & 1.541 & 2.424 & -0.005 & 0.710 \\
$p_{2}=1 \mathrm{ksi}$ & -1.389 & -2.311 & -0.996 & -0.710 \\
\hline
\end{tabular}


$=E \cdot \alpha\left(T_{m}-T_{s}\right) /(1-v)$. Fig. A-8153.1 Eq. (24) [3] incorporates a stress reduction factor, $K_{\text {skin }}$ based on the nominal ligament efficiency $(\eta=0.25)$ for the purpose of adjusting the thermal skin stresss, so it can be combined with the stresses from all of the other load cases using the equivalent solid plate method. Table 2 shows the thermal skin stresses for $\Delta T=\left(T_{m}-\right.$ $\left.T_{s}\right)=100^{\circ} \mathrm{F}$. Thermal skin stress is classified as peak stress $(F)$.

\section{Tube Internal Pressure Ligament Stresses}

A-8110 (b) [3] acknowledges that the tubes stiffen the tubesheet. Nuclear steam generator tubes are expanded full depth into the tubesheet holes, increasing the tubesheet stiffness. This effect is conservatively ignored in this analysis; but this could be included if needed, to confirm structural acceptability.

The influence of the pressure loading inside the tubes is included, because it produces membrane stresses in the tubesheet ligaments. This effect is addressed in Eq. (13) of A-8132.4 [3]. This equation incorporates a stress reduction factor $h / P$, that adjusts the stresses due to the tube internal pressure, so they can be combined with the stresses from the other load cases that are based on the equivalent solid plate properties. The ratio of Young's modulus for the tube $\left(E_{t}\right)$ to the Young's modulus of the tubesheet material $(E)$ is included to account for the different properties of the tube and the tubesheet ligament. The ligament stresses due to tube internal pressure are listed in Table 3.

Table 2 Thermal skin stresses for $100 \mathrm{oF} \Delta \mathrm{T}$.

\begin{tabular}{lllcc}
\hline $\begin{array}{l}\text { Thermal peak, } F \\
\text { sec. side node }\end{array}$ & $\begin{array}{l}\sigma_{r}{ }^{*} \\
(\mathrm{ksi})\end{array}$ & $\begin{array}{l}\sigma_{\theta}{ }^{*} \\
(\mathrm{ksi})\end{array}$ & $\begin{array}{l}\sigma_{a}{ }^{*} \\
(\mathrm{ksi})\end{array}$ & $\begin{array}{l}\tau_{r a}{ }^{*} \\
(\mathrm{ksi})\end{array}$ \\
\hline$\Delta T=100^{\circ} \mathrm{F}$ & 5.823 & 5.823 & 0 & 0 \\
\hline
\end{tabular}

Table 3 Ligament membrane stress due to tube internal pressure (unit load case).

\begin{tabular}{llllc}
\hline $\begin{array}{l}\text { Membrane, } P_{m} \\
\text { sec. side node }\end{array}$ & $\begin{array}{l}\sigma_{r}{ }^{*} \\
(\mathrm{ksi})\end{array}$ & $\begin{array}{l}\sigma_{\theta}{ }^{*} \\
(\mathrm{ksi})\end{array}$ & $\begin{array}{l}\sigma_{a}{ }^{*} \\
(\mathrm{ksi})\end{array}$ & $\begin{array}{c}\tau_{r a}{ }^{*} \\
(\mathrm{ksi})\end{array}$ \\
\hline$p_{i}=1 \mathrm{ksi}$ & 0.497 & 0.497 & 0 & 0 \\
\hline
\end{tabular}

\section{Primary Stress Evaluation}

The NB-3221.1 primary membrane stress intensity requirement [7] is to be satisfied based on the stresses due to mechanical and pressure loads. The membrane stress is averaged across the nominal ligament width (0.25 inch) and across the tubesheet thickness as required by A-8142.1 (a) [3].

Using the membrane values of Tables 1 and 3, the radial stress, averaged through the depth of the equivalent solid plate for DS1, and the larger value of Eqs. (16) and (17) [3] are calculated in Table 4.

The NB-3221.3 primary membrane plus bending stress intensity requirement [7] is to be satisfied based on the stresses due to mechanical and pressure loads. The stresses at the surface of the tubesheet are averaged across the nominal ligament width $(0.25$ inch), as required by A-8142.1 (b) [3].

Using the membrane plus bending values of Table 1 and membrane of Table 3, the radial and hoop stresses for DS1 are calculated in Table 5, according to Eq. (18) [3]:

$$
S=K(P / h) \cdot \sigma_{a v e} *
$$

\section{Primary Plus Secondary Stress Range}

The NB-3222.2 primary plus secondary stress intensity range requirement [7] is to be satisfied based on the stresses due to mechanical, pressure, and the gross thermal interaction loads. The stresses at the surface of the tubesheet are averaged across the nominal ligament width $(0.25 \mathrm{inch})$, as required by A-8142.2 (a) [3].

Using the membrane plus bending values of Table 5 and the gross thermal stresses, the radial and hoop stress for DS1 is calculated in Table 6, according to Eq. (19) [3]:

$$
S=K(P / h) \cdot \sigma_{1}^{*}
$$

\section{Peak Stress Intensity and Fatigue}

The peak stress intensity due to all loadings is limited by the NB-3222.4 cyclic fatigue requirement [7]. The total stresses at the surface of the tubesheet 
Table 4 Primary membrane stress.

\begin{tabular}{llllll}
\hline $\begin{array}{l}\text { Membrane, } P_{m} \\
\text { @sec. side node }\end{array}$ & $\begin{array}{l}p_{1}=p_{i} \\
(\mathrm{ksi})\end{array}$ & $\begin{array}{l}p_{2} \\
(\mathrm{ksi})\end{array}$ & $\begin{array}{l}\sigma_{r}{ }^{*} \\
(\mathrm{ksi})\end{array}$ & $\begin{array}{l}S \\
(\mathrm{ksi})\end{array}$ & $\begin{array}{l}\text { Limit } \\
(\mathrm{ksi})\end{array}$ \\
\hline Design & 2.500 & 0.900 & 1.952 & 12.003 & 30.000 \\
Level A \& B & 2.700 & 0.800 & 2.107 & 13.719 & 33.000 \\
Level C & 2.600 & 0.000 & 2.023 & 16.879 & 48.510 \\
Level D & 2.800 & 0.000 & 2.178 & 18.177 & 63.000 \\
Test & 3.100 & 0.000 & 2.412 & 20.125 & 54.140 \\
\hline
\end{tabular}

Table 5 Primary membrane plus bending stress.

\begin{tabular}{lcccccc}
\hline $\begin{array}{l}\text { Mem + bend } \\
\text { sec. side node }\end{array}$ & $\begin{array}{l}\sigma_{r}{ }^{*} \\
(\mathrm{ksi})\end{array}$ & $\begin{array}{c}\sigma_{\theta}{ }^{*} \\
(\mathrm{ksi})\end{array}$ & $\beta$ & $K$ & $\begin{array}{l}S \\
(\mathrm{ksi})\end{array}$ \\
\cline { 2 - 5 } & \multicolumn{2}{c}{$P_{m+b}$} & $\begin{array}{l}\text { Limit } \\
(\mathrm{ksi})\end{array}$ \\
\hline Design & 3.845 & 5.223 & 0.74 & 1.01 & 21.099 & 45.000 \\
Level A \& B & 4.391 & 6.038 & 0.73 & 1.01 & 24.393 & 49.500 \\
Level C & 5.299 & 7.595 & 0.70 & 1.01 & 30.682 & 72.765 \\
Level D & 5.706 & 8.179 & 0.70 & 1.01 & 33.042 & 94.500 \\
Test & 6.318 & 9.055 & 0.70 & 1.01 & 36.583 & 81.210 \\
\hline
\end{tabular}

Table 6 Primary plus secondary stress range.

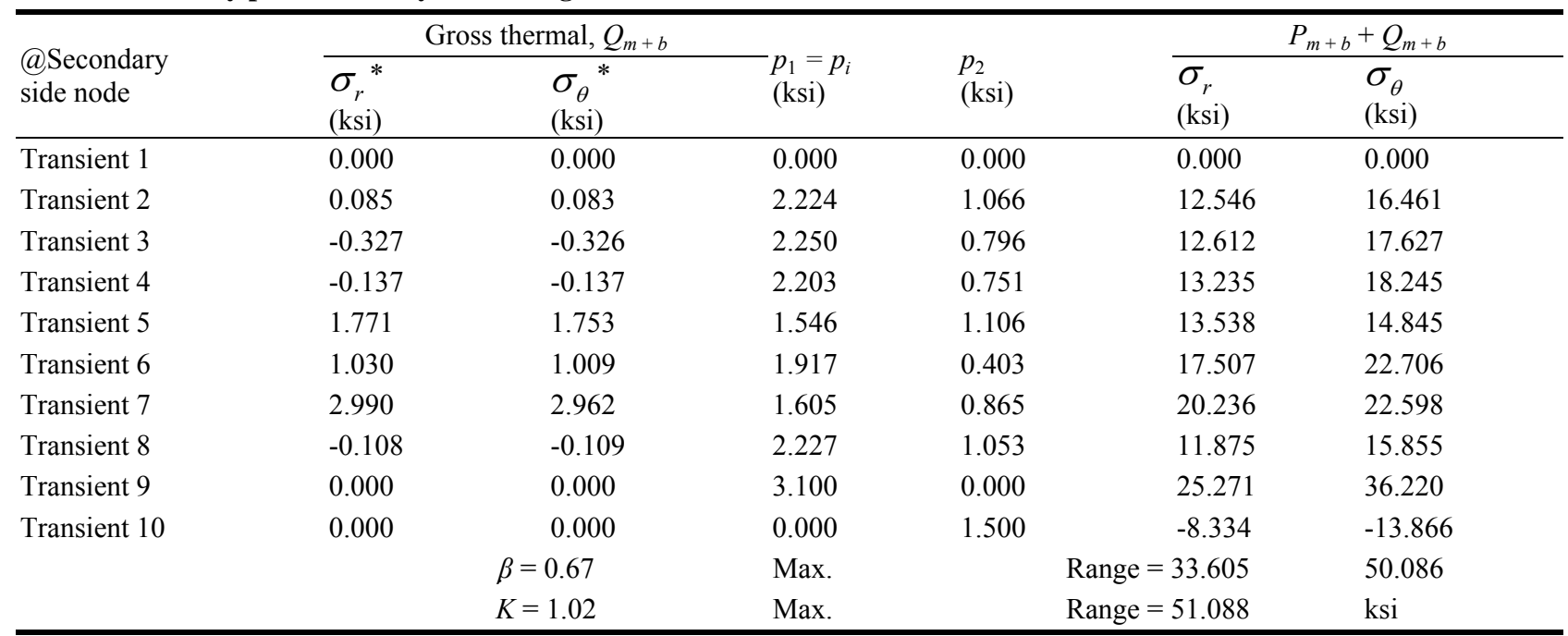

at the nominal ligament are calculated as required by Figs. A-8142.2b or c [3]. A-8142.2 (b) and (c) both deal with the calculation of the peak stress intensity; but Eq. (20) $S=Y_{\max } \cdot(P / h) \cdot \sigma_{1} *+p_{s}$, is only intended for loadings where the maximum stress intensity angular orientation is constant.

In most practical cases (and the example of this paper) the bi-axiality ratio $(\beta)$ for pressure stresses and thermal stresses are different and vary during the transient history, and the principal stress angular orientations change during the transient history, so Eq. (21) $S_{\Phi}=Y_{1} \sigma_{1} * / \eta+Y_{2} \sigma_{2} * / \eta+p_{s}$ used.
In 2012, the ASME Section III Code Interpretations Committee ruled that the label "(c)" was an editorial error [6], thus confirming that both Eqs. (20) and (21) [3] were intended as alternatives.

The peak stress intensity around the periphery of the hole at location DS1 is provided by Eq. (21) of Fig. A-8142.2c [3]. The angular orientation of the mis-drilled hole to the tubesheet drilling pattern (angle $\Phi)$ must be determined, so that the stress multipliers from Figs. A-8142-3 and A-8142-4 can be determined. Following is Eq. (21) from [3].

$$
S_{\Phi}=Y_{1} \sigma_{1} * / \eta+Y_{2} \sigma_{2} * / \eta+p_{s}
$$


where, $S_{\Phi}=$ peak stress intensity at the angular orientation $\Phi$;

Figs. A-8142-3 and A-8142-4 are used, because they most closely match the angular orientation of the holes at DS1 (Fig. 4) where the angle is $5.8^{\circ}$ from the actual radial orientation (for this location $\sigma_{2}$ ), which is less than the $7.5^{\circ}$ value of applicability;

$\eta=$ nominal ligament efficiency $(0.25)$;

$\sigma_{1}{ }^{*}$ and $\sigma_{2} *$ are based on all loadings (except the ligament stresses due to the pressure in the tubes (Eq. (13) [3]).

For angles $\Phi=30^{\circ}$ and $\Phi=90^{\circ}$, the ligament stresses due to the pressure in the tubes have the maximum values in Eq. (13) [3] without any stress concentration factor, because it is calculated based on the real geometry (Fig. 5).

$$
\sigma_{r}=\sigma_{\theta}=\frac{F}{A}=\frac{\left(d-2 \cdot t_{t}\right)_{t} \cdot p_{i} \cdot t}{\left(h+2 \cdot \frac{E_{t}}{E} \cdot t_{t}\right) \cdot t}=\frac{\left(P-h-2 \cdot t_{t}\right)}{\left(h+2 \cdot \frac{E_{t}}{E} \cdot t_{t}\right)} \cdot p_{i}
$$

The peak stress intensity is determined for all time steps of all transients for the fatigue evaluation.

The total stress results at location DS1 are listed in Table 7 . Table 8 shows the stress intensity calculated using Eq. (21) [3] for two representative angles around the hole, $0^{\circ}$ and $90^{\circ}$. Finally, Table 9 shows the factors from Figs. A-8142-3 and A-8142-4 [3] and the cumulative usage factors for nominal ligament.

\section{Stress Evaluation-Thin Ligament}

Table NB-3217-1 [7] classifies the stress intensities

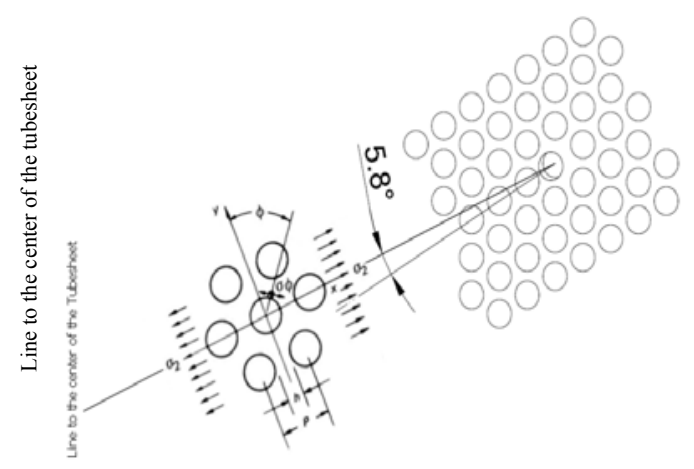

Fig. 4 Relative location of the deviated hole respect to the radial orientation.

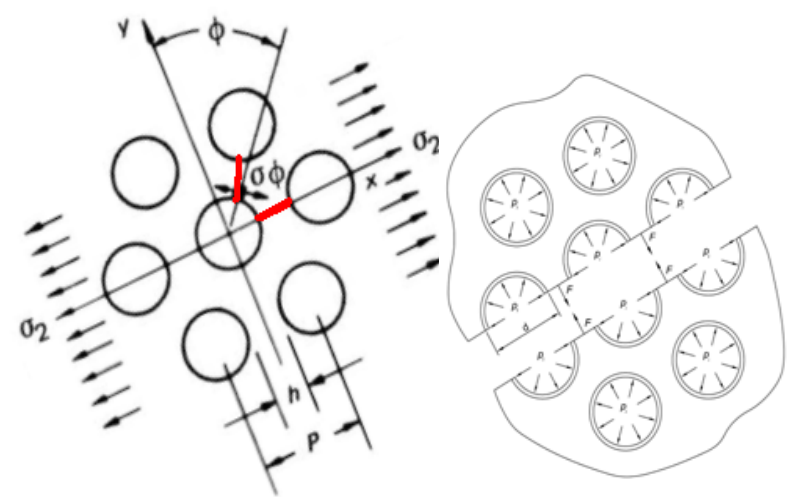

Fig. 5 Eq. (13) [3] to be added to $S_{\Phi}$ of Eq. (21) [3].

at an isolated or atypical ligament (such as that found next to a mis-drilled hole). It states that membrane stress due to pressure is classified as secondary $(Q)$ and bending is classified as peak $(F)$. This means that the mis-drilled hole does not change the tubesheet primary stress margins for the design condition, service levels A, B, C and D, and/or the test condition for the tubesheet with nominal ligaments. The Triaxial stress requirement is also satisfied, because it is based on primary stresses.

The stress limits that must be satisfied at an irregular or thin ligament are found in Fig. A-8143 [3]. Fig. A-8143 requires evaluation of the Average Stress Intensity at the mid-surface of the tubesheet (A-8143.1) and peak stress intensity (fatigue) (A-8143.2) at the tubesheet surface.

\section{Average Stress Intensity Limit (A-8143.1)}

Fig. A-8143.1 limits the average ligament stress intensity due to pressure plus other mechanical loads to $3.0 S_{m}$. The gross thermal discontinuity stresses should also be included (although not mentioned). This is consistent with the original work of O'Donnell [1] in his discussion of the thin ligament, and is consistent with the definition of secondary stresses. This stress intensity is based on stresses averaged across the thin ligament width and the tubesheet thickness (thus removing bending). This evaluation is similar to that performed to evaluate primary membrane in Fig. A-8142.1 (a) except that the actual width of the thin ligament $\left(h_{a}\right)$ is used in place of the 
Table 7 Total stresses-nominal ligament.

\begin{tabular}{lllllc}
\hline $\begin{array}{l}\text { Total stress } \\
\text { @ Sec. side node }\end{array}$ & $\begin{array}{c}p_{1}=p_{i} \\
(\mathrm{ksi})\end{array}$ & $\begin{array}{c}p_{2}=p_{s} \\
(\mathrm{ksi})\end{array}$ & $\begin{array}{c}\Delta T \\
\left({ }^{\circ} \mathrm{F}\right)\end{array}$ & $\begin{array}{l}\sigma_{2}{ }^{*}=\sigma_{r}^{*} \\
(\mathrm{ksi})\end{array}$ & $\begin{array}{c}\sigma_{1}^{*}=\sigma_{\theta}^{*} \\
(\mathrm{ksi})\end{array}$ \\
\hline Transient 1 & 0.000 & 0.000 & 0 & 0.000 & 0.000 \\
Transient 2 & 2.224 & 1.066 & 91 & 7.319 & 8.297 \\
Transient 3 & 2.250 & 0.796 & 92 & 7.409 & 8.663 \\
Transient 4 & 2.203 & 0.751 & 93 & 7.618 & 8.870 \\
Transient 5 & 1.546 & 1.106 & -167 & -7.114 & -6.787 \\
Transient 6 & 1.917 & 0.403 & -117 & -3.389 & -2.089 \\
Transient 7 & 1.605 & 0.865 & -239 & -9.673 & -9.082 \\
Transient 8 & 2.227 & 1.053 & 93 & 7.283 & 8.278 \\
Transient 9 & 3.100 & 0.000 & 0 & 4.777 & 7.514 \\
Transient 10 & 0.000 & 1.500 & 0 & -2.084 & -3.467 \\
\hline
\end{tabular}

Table 8 Peak stress intensity at $0^{\circ} \& 90^{\circ}$, nominal ligament.

\begin{tabular}{llll}
\hline $\begin{array}{l}\text { Total stress } \\
\text { @ Sec. side node }\end{array}$ & Cycles & $\begin{array}{l}S_{\Phi}=0^{\circ} \\
(\mathrm{ksi})\end{array}$ & $\begin{array}{l}S_{\Phi}=90^{\circ} \\
(\mathrm{ksi})\end{array}$ \\
\hline Transient 1 & 400 & 0.000 & 0.000 \\
Transient 2 & 6,000 & 22.128 & 43.850 \\
Transient 3 & 6,000 & 20.699 & 45.370 \\
Transient 4 & 200 & 21.411 & 46.184 \\
Transient 5 & 10 & -26.269 & -26.977 \\
Transient 6 & 50 & -18.816 & -5.136 \\
Transient 7 & 15 & -37.148 & -37.606 \\
Transient 8 & $1,000,000$ & 21.899 & 43.759 \\
Transient 9 & 10 & 2.416 & 41.277 \\
Transient 10 & 10 & 1.468 & -14.723 \\
\hline
\end{tabular}

Table 9 Stress multipliers and CUF-nominal ligament.

\begin{tabular}{llll}
\hline Angle & $Y_{1}$ & $Y_{2}$ & $C U F$ \\
\hline $0^{\circ}$ & -1.35 & 2.25 & 0.0015 \\
$10^{\circ}$ & -1.15 & 2.15 & 0.0027 \\
$20^{\circ}$ & -0.6 & 1.75 & 0.0055 \\
$30^{\circ}$ & 0.3 & 0.8 & 0.0076 \\
$40^{\circ}$ & 1.05 & 0 & 0.0065 \\
$50^{\circ}$ & 1.4 & -0.4 & 0.0062 \\
$60^{\circ}$ & 1.3 & -0.47 & 0.0033 \\
$70^{\circ}$ & 1.25 & -0.27 & 0.0055 \\
$80^{\circ}$ & 1.22 & -0.15 & 0.0072 \\
$90^{\circ}$ & 1.2 & -0.05 & 0.0124 \\
\hline
\end{tabular}

nominal width $h$. The membrane stress components from the equivalent solid plate for the nominal ligament that were multiplied by the $P / h$ ratio are changed using the $P / h_{a}$ ratio for actual thin ligament.

The A-8143.1 methodology [3] is based on the conservative assumption that a mis-drilled hole is parallel to its neighbors and that the actual thin ligament extends through the entire tubesheet thickness. Since actual mis-drilled holes are not typically parallel to the neighboring holes, it is necessary to determine the ligament width at the tubesheet mid-surface, $h_{m}$ and to use it in the A-8143.1 evaluation. A linear variation in the ligament thickness is conservative for typical mis-drilled holes. Using this assumption, the actual mid-surface ligament for use in the A-8143.1 evaluation is $h_{m}=\left(h+h_{a}\right) / 2$. The average stress intensity results for the irregular or thin ligament are shown in Table 10. All values are less than the allowable $3 S_{m}(90 \mathrm{ksi})$ value.

\section{Peak Stress Intensity Limit (A-8143.2)}

Paragraph A-8143.2 [3] describes the method for obtaining the peak stress intensity for a thin ligament. The thin ligament peak stress intensity is computed by multiplying the nominal peak stress intensity (for the nominal ligament) by the $K_{m}$ value from Fig. A-8143.2-1 [3]. The $K_{m}$ minimum ligament multiplier and the peak stress intensity are calculated at each transient load step. The stresses from all of the loadings (i.e., pressure, gross thermal stresses and skin stresses) are superimposed at each load step to determine the ratio of the two principal stresses $(\beta)$. Then a value for $K_{m}$ is extracted from Fig. A-8143.2-1 [3] by linear interpolation between the two nearest plotted $\beta$ values (either $\beta=-1,0$, or +1 ). 
Table 10 Primary plus secondary stresses-thin ligament.

\begin{tabular}{|c|c|c|c|c|c|c|}
\hline \multirow{3}{*}{ @ sec. side node } & \multicolumn{2}{|c|}{ Gross thermal } & \multirow[b]{2}{*}{$\begin{array}{c}p_{1}=p_{i} \\
(\mathrm{ksi})\end{array}$} & \multirow[b]{2}{*}{$\begin{array}{l}p_{2} \\
(\mathrm{ksi})\end{array}$} & \multirow{2}{*}{$\begin{array}{l}\sigma_{r} \\
(\mathrm{ksi})\end{array}$} & \multirow{2}{*}{$\begin{array}{l}\sigma_{\theta} \\
(\mathrm{ksi})\end{array}$} \\
\hline & $\begin{array}{l}\sigma_{r}{ }^{*} \\
(\mathrm{ksi})\end{array}$ & $\begin{array}{l}\sigma_{\theta}^{*} \\
(\mathrm{ksi})\end{array}$ & & & & \\
\hline & \multicolumn{2}{|c|}{$Q_{m+b}$} & & & \multicolumn{2}{|c|}{$P_{m}+Q_{m+b}$} \\
\hline Transient 1 & 0.000 & 0.000 & 0.000 & 0.000 & 0.000 & 0.000 \\
\hline Transient 2 & 0.085 & 0.083 & 2.224 & 1.066 & 10.057 & 9.684 \\
\hline Transient 3 & -0.327 & -0.326 & 2.250 & 0.796 & 9.572 & 9.230 \\
\hline Transient 4 & -0.137 & -0.137 & 2.203 & 0.751 & 9.632 & 9.299 \\
\hline Transient 5 & 1.771 & 1.753 & 1.546 & 1.106 & 9.451 & 9.129 \\
\hline Transient 6 & 1.030 & 1.009 & 1.917 & 0.403 & 10.012 & 9.719 \\
\hline Transient 7 & 2.990 & 2.962 & 1.605 & 0.865 & 11.445 & 11.127 \\
\hline Transient 8 & -0.108 & -0.109 & 2.227 & 1.053 & 9.795 & 9.424 \\
\hline Transient 9 & 0.000 & 0.000 & 3.100 & 0.000 & 13.782 & 13.427 \\
\hline \multirow[t]{3}{*}{ Transient 10} & 0.000 & 0.000 & 0.000 & 1.500 & 0.069 & -0.094 \\
\hline & & 0.99 & Max. & Range & 13.713 & 13.522 \\
\hline & $K$ & 1.00 & Max. & Range & 13.713 & ksi \\
\hline
\end{tabular}

Fig. A-8143.2a states that the peak stress intensity in the nominal ligament is calculated as indicated in Fig. A-8142.2b. As written, this cross-reference could be interpreted to exclude the use of the Fig. A-8142.2c to calculate the peak stress intensity, but such an interpretation was not intended. This incomplete cross-reference was not present in the original text of the 1966 Addenda [2] when it was first introduced. The ASME Section III Committee for Code Interpretations confirmed that this was an editorial error that will be corrected in a future code edition [6].

\section{Peak Stress Intensity Evaluation}

Eq. (21) [3] is modified to account for the thin ligament by multiplying the total stress for the nominal thickness ligament by the $K_{m}$ value from Fig. A-8143.2-1 [3]. Therefore, the modified Eq. (21) appears as follows:

$$
S_{\Phi-\text { thin }}=\left(Y_{1} \sigma_{1} * / \eta+Y_{2} \sigma_{2} * / \eta\right) \cdot K_{m}+p_{s}
$$

The peak stress intensities are calculated for each of the transient stress states considered in the fatigue evaluation.

Special consideration is required for angles $\Phi=30^{\circ}$ and $\Phi=90^{\circ}$. In these angles, the ligament stresses due to the pressure in the tubes have the maximum values and it is added (Eq. (13) [3]) without any stress concentration factor, because it is calculated in the real geometry. For other angles, this stress can be considered negligible (Fig. 5). Therefore, for the thin ligament:

$$
\begin{gathered}
S_{\Phi-\text { thin }}\left(30^{\circ} \& 90^{\circ}\right) \\
=\left(\frac{Y_{1} \sigma_{1}^{*}+Y_{2} \sigma_{2}^{*}}{\eta}\right) K_{m}+p_{s}+\frac{\left(d-2 \cdot t_{t}\right) \cdot p_{i}}{\left(h_{m}+2 \cdot \frac{E_{t}}{E} \cdot t_{t}\right)}
\end{gathered}
$$

Tables 11-13 show the result of the process to obtain the stress intensity and cumulative usage factors for fatigue in a thin or irregular ligament.

The results of the analysis for the nominal 0.25 "

Table 11 Total stress - thin ligament.

\begin{tabular}{lllll}
\hline $\begin{array}{l}\text { Total stress }(P \\
+Q+F)_{m+b} \\
\text { Sec. side node }\end{array}$ & $\begin{array}{l}\sigma_{2}{ }^{*}=\sigma_{r}{ }^{*} \\
(\mathrm{ksi})\end{array}$ & $\begin{array}{l}\sigma_{1}{ }^{*}=\sigma_{\theta}{ }^{*} \beta \\
(\mathrm{ksi})\end{array}$ & $K_{m}$ \\
\hline Transient 1 & 0.000 & 0.000 & 0.00 & 2.50 \\
Transient 2 & 7.319 & 8.297 & 0.88 & 2.06 \\
Transient 3 & 7.409 & 8.663 & 0.86 & 2.07 \\
Transient 4 & 7.618 & 8.870 & 0.86 & 2.07 \\
Transient 5 & -7.114 & -6.787 & 0.95 & 2.02 \\
Transient 6 & -3.389 & -2.089 & 0.62 & 2.19 \\
Transient 7 & -9.673 & -9.082 & 0.94 & 2.03 \\
Transient 8 & 7.283 & 8.278 & 0.88 & 2.06 \\
Transient 9 & 4.777 & 7.514 & 0.64 & 2.18 \\
Transient 10 & -2.084 & -3.467 & 0.60 & 2.20 \\
\hline
\end{tabular}


Table 12 Peak stress intensity at $0^{\circ}$ and $90^{\circ}$-thin ligament.

\begin{tabular}{llll}
\hline $\begin{array}{l}\text { Total stress } \\
\text { @sec. side node }\end{array}$ & Cycles & $\begin{array}{l}S_{\Phi-\text { thin }}=0^{\circ} \\
(\mathrm{ksi})\end{array}$ & $\begin{array}{l}S_{\Phi-\text { thin }}=90^{\circ} \\
(\mathrm{ksi})\end{array}$ \\
\hline Transient 1 & 400 & 0.000 & 0.000 \\
Transient 2 & 6,000 & 44.433 & 85.736 \\
Transient 3 & 6,000 & 42.042 & 89.648 \\
Transient 4 & 200 & 43.530 & 91.385 \\
Transient 5 & 10 & -54.272 & -57.972 \\
Transient 6 & 50 & -41.720 & -15.193 \\
Transient 7 & 15 & -76.321 & -79.628 \\
Transient 8 & $1,000,000$ & 43.998 & 85.601 \\
Transient 9 & 10 & 5.272 & 84.543 \\
Transient 10 & 10 & 1.429 & -34.181 \\
\hline
\end{tabular}

Table 13 Stress multipliers and CUF-thin ligament.

\begin{tabular}{llll}
\hline Angle & $Y_{1}$ & $Y_{2}$ & $C U F$ \\
\hline $0^{\circ}$ & -1.35 & 2.25 & 0.0226 \\
$10^{\circ}$ & -1.15 & 2.15 & 0.0336 \\
$20^{\circ}$ & -0.60 & 1.75 & 0.0595 \\
$30^{\circ}$ & 0.30 & 0.80 & 0.0767 \\
$40^{\circ}$ & 1.05 & 0.00 & 0.0722 \\
$50^{\circ}$ & 1.40 & -0.40 & 0.0705 \\
$60^{\circ}$ & 1.30 & -0.47 & 0.0413 \\
$70^{\circ}$ & 1.25 & -0.27 & 0.0638 \\
$80^{\circ}$ & 1.22 & -0.15 & 0.0795 \\
$90^{\circ}$ & 1.20 & -0.05 & 0.1088 \\
\hline
\end{tabular}

Table 14 Nominal vs. thin ligament results.

\begin{tabular}{llcl}
\hline $\begin{array}{l}\text { Asme section III } \\
\text { code limit }\end{array}$ & $\begin{array}{l}\text { Nominal } \\
\text { in.) ligament }\end{array}$ & $\begin{array}{l}(0.25 \text { thin } \\
\text { ligament }\end{array}$ & in. $)$ \\
\hline $\begin{array}{l}\text { Primary plus secondary } \\
\text { stress intensity range }\end{array}$ & $51.088 \mathrm{ksi}$ & $13.713 \mathrm{ksi}$ & \\
$\begin{array}{l}\text { Cumulative fatigue } \\
\text { usage factor, cuf }\end{array}$ & 0.0124 & 0.1008 & \\
\hline
\end{tabular}

tubesheet ligament are compared to those of the thin 0.10 " ligament in Table 14. This comparison shows that the mis-drilled hole does not impact the primary plus secondary stress intensity range because of the different classification of stresses in a single, thin ligament (Table NB-3217-1 [7]). The main influence of the mis-drilled hole is to increase the cumulative fatigue usage factor.

\section{Conclusions}

The methodology used to evaluate the structural integrity of a steam generator tubesheet with a mis-drilled hole is described and explained. The non-mandatory rules of ASME Appendix A, Article A-8000 [3] contains several ambiguities that are addressed and clarified. The analysis is applied to an actual, non-parallel mis-drilled hole and compared to a parallel mis-drilled hole as is assumed in Appendix A. It is shown that the main influence of a mis-drilled hole is on the cumulative fatigue usage factor.

This method does not account for load redistribution around a thin ligament, so the fatigue result is conservative. The presence of mis-drilled holes or locally thin ligaments does not affect the primary stress margin in the tubesheet and does not reduce its overall structural integrity. Therefore, there is no consequence of a fatigue crack at any point within the tubesheet drilling-pattern, because it could not propagate beyond the local ligament. Consequently, the presence of mis-drilled holes within the tubesheet drilling pattern, although it may complicate tube installation, is a structurally acceptable condition.

\section{Acknowledgments}

The authors would like to acknowledge the contribution of ENSA (Equipos Nucleares S.A.) and Enrique Casado in the development of this report.

\section{References}

[1] O'Donnell, W. J., and Langer, B. F. 1962. "Design of Perforated Plates." Journal of Engineering for Industry 84 (3): 307-19.

[2] ASME Boiler \& Pressure Vessel Code, Section III. 1965. Rules for Construction of Nuclear Power Plant Components. 1965 Edition with Addenda through Summer 1966, Appendix I, Article I-9 "Stresses in Ligaments." New York: The American Society of Mechanical Engineers.

[3] ASME Boiler \& Pressure Vessel Code, Section III. 2010. Rules for Construction of Nuclear Power Plant Components. 2010 Edition, 2011 Addenda, Division 1 Appendices, Appendix A, Article A-8000 "Stresses in Perforated Flat Plates.” New York: The American Society of Mechanical Engineers.

[4] Thomas, S. 1972. Stress Analysis of Thick Perforated Plates. Westport: Technomic Publishing Co. Inc. 
[5] ANSYS Computer Program Release 10.0 A1. 275 Technology Dr., Canonsburg, PA 15317. South Point: ANSYS Inc.

[6] ASME Code Inquiry File: 12-1333. 2012. Letter from Ms. Allyson Byk, Secretary, Section III Standards Committee to inquirer Robert Wilson.

[7] ASME Boiler \& Pressure Vessel Code, Section III. 2010.
Rules for Construction of Nuclear Power Plant Components. 2010 Edition, 2011 Addenda, Subsection NB. New York: The American Society of Mechanical Engineers.

[8] ASME Boiler and Pressure Vessel Code Section II-D.2010. Material Properties. 2010 Edition, 2011 Addenda. New York: The American Society of Mechanical Engineers. 